\title{
Characterization of nitrergic function in monkey penile erection in vivo and in vitro
}

\author{
Kazuhide Ayajiki ${ }^{1,2}$, Hideshi Hayashida ${ }^{1}$, Masashi Tawa ${ }^{1}$, Tomio Okamura ${ }^{1}$ and Noboru Toda ${ }^{1,3}$
}

The nitrergic nerve appears to have a major role in the neuronal regulation of penile erection. Cholinergic innervation has been shown histochemically in penile cavernous tissues, but its functional role is not well understood. This study was aimed at examining the functional properties of the nitrergic nerve and the possible involvement of cholinergic function in the regulation of monkey penile erection in vivo and in vitro. In anesthetized Japanese monkeys, electrical stimulation of the cavernous nerve caused a frequency-dependent increase in intracavernous pressure and penile erection, and atropine enhanced the pressure response. Intravenous injections of $N^{G}$-nitro-L-arginine (L-NA) markedly inhibited the stimulation-induced pressure increase and the erectile response, and L-arginine partially restored the pressure response. In some monkeys, the intracavernous pressure increase caused by nerve stimulation was reversed by treatment with L-NA; however, L-arginine restored the pressor response. In addition, hexamethonium suppressed the pressure increase that resulted from the nerve stimulation. In corpus cavernosum isolated from monkeys, transmural electrical stimulation elicited frequency-dependent relaxation. The relaxation was attenuated by physostigmine, and was potentiated by atropine. Relaxation was markedly inhibited by treatment with L-NA. It appears that nitric oxide (NO) released from inhibitory nerves, even at low frequencies, has a pivotal role in the initiation and maintenance of intracavernous pressure increase and penile erection in monkeys. Prejunctional muscarinic receptors in nitrergic nerves are expected to participate in the impairment of NO release. Nitrergic nerves responsible for penile erection may originate from ganglia close to the corpus cavernosum.

Hypertension Research (2009) 32, 685-689; doi:10.1038/hr.2009.84; published online 5 June 2009

Keywords: corpus cavernosum; intracavernous pressure; nerve stimulation; nitric oxide; prejunctional muscarinic receptor

\section{INTRODUCTION}

The function of nitric oxide (NO) as a neurotransmitter in nonadrenergic, noncholinergic nerves responsible for penile erection was first determined in the corpus cavernosum isolated from rabbits. ${ }^{1}$ The presence of NO-synthase-containing nerve fibers in the corpora cavernosa and the involvement of NO in the intracavernous pressure increase by electrical stimulation of the cavernous nerve in anesthetized rats were outlined by Burnett et al. ${ }^{2}$ The role of neurogenic NO in penile erection has been shown in a variety of experimental animals. ${ }^{3-5}$ Involvement of the $\mathrm{NO}-$ cyclic GMP pathway in the relaxation of human corpus cavernosum strips in response to electrical field stimulation has also been shown. ${ }^{6-9}$ Efficacy of phosphodiesterase- 5 inhibitors in patients with erectile dysfunction supports the idea that cyclic GMP formed by NO-mediated activation of guanylyl cyclase has an important role in penile tumescence. ${ }^{10}$ Recent studies suggest that NO released from the sinusoidal endothelium is also involved in the maintenance of penile erection. ${ }^{11}$

Although cholinergic innervation has been shown in the penile corpus cavernosum, the functional role has not been elucidated. ${ }^{12,13}$ Furthermore, reports in the literature have revealed interspecies variation in the responses to efferent nerve stimulation of the isolated corpus cavernosum. Differences in the responses of erectile tissues have also been shown between isolated preparations and anesthetized animals. It is important to determine how data obtained from experimental mammals can be applied to humans in vivo; however, information about primates in vivo is lacking. This study was undertaken to analyze the mechanisms that underlie the intracavernous pressure responses to electrical stimulation of the cavernous nerve in anesthetized monkeys, to compare these responses to those obtained from subprimate mammals, and to determine whether endogenous acetylcholine and endothelial NO are involved in the regulation of nitrergic nerve function in vivo and in vitro.

\section{METHODS}

Animals

The Animal Care and Use Committee at the Shiga University of Medical Science approved this study. The number of Japanese monkeys (Macaca fuscata) used for this project was 10 (four for the in vivo study and six for the in vitro study).

\footnotetext{
${ }^{1}$ Department of Pharmacology, Shiga University of Medical Science, Seta, Otsu, Japan; ${ }^{2}$ Department of Pharmacology, School of Pharmacy, Hyogo University of Health Sciences, Chuo-ku, Kobe, Japan and ${ }^{3}$ Toyama Institute for Cardiovascular Pharmacology Research, Chuo-ku, Osaka, Japan 


\section{In vivo study}

Four male monkeys, weighing $10-15 \mathrm{~kg}$, were premedicated with an intramuscular injection of ketamine $\left(15 \mathrm{mg} \mathrm{kg}^{-1}\right)$ and anesthetized with pentobarbital sodium $\left(20 \mathrm{mg} \mathrm{kg}^{-1}\right)$ given intravenously. Stable anesthetic conditions were maintained by additional injections as needed. The animals were intubated for spontaneous breathing. Arterial pressures were monitored with a pressure transducer (MPU0.5, Toyo Measuring Instruments, Tokyo, Japan) and amplifier (AP641G, Nihon-Kohden Kogyo, Tokyo, Japan) through a catheter inserted into the right femoral artery. The lower abdomen was opened through a midline abdominal incision. The left cavernous nerve derived from the pelvic plexus was carefully isolated and placed on a bipolar electrode (Iwashiya Kishimoto Medical Instruments, Kyoto, Japan) connected to an electronic stimulator (Nihon-Kohden Kogyo). To measure the intracavernous pressure, a 21-gauge needle was placed in the cavity of the left corpus cavernosum for connecting to the pressure transducer and recorder. Drugs were administered systemically through the right femoral vein. The cavernous nerve was stimulated by $1.0 \mathrm{~ms}$ electrical square pulses of $10 \mathrm{~V}$ in frequencies of $0.5,1,2,5,10$ and $20 \mathrm{~Hz}$ for a period of $20 \mathrm{~s}$ at intervals of $10-15 \mathrm{~min}$. After the stabilization of intracavernous pressor responses to the nerve stimulation, atropine $\left(1 \mathrm{mg} \mathrm{kg}^{-1}\right), \quad N^{G}$-nitro-L-arginine (L-NA; $5 \mathrm{mg} \mathrm{kg}^{-1}$ ) or hexamethonium $\left(4 \mathrm{mg} \mathrm{kg}^{-1}\right)$ was administered intravenously. After the pressor responses at different frequencies were obtained under treatment with L-NA, L-arginine ( $500 \mathrm{mg} \mathrm{kg}^{-1}$ ) was slowly infused into the femoral vein. Thus, the effects of several agents on intracavernous pressure were obtained.

\section{In vitro study}

Six male monkeys, weighing $8-10 \mathrm{~kg}$, were anesthetized with ketamine $\left(40 \mathrm{mg} \mathrm{kg}^{-1}\right.$, intramuscular) and sodium pentobarbital $\left(30 \mathrm{mg} \mathrm{kg}^{-1}\right.$, i.v.). The animals were subsequently killed by bleeding from the carotid arteries. The penis was removed, and the corpora cavernosa were isolated. The tunica albuginea was removed, and $2-4$ strips $(\sim 3 \times 5 \times 10 \mathrm{~mm})$ from each individual corpus were obtained. Each specimen was vertically fixed between hooks in a muscle bath ( $10 \mathrm{ml}$ capacity) containing a modified Ringer-Locke solution of the following composition $\left(\mathrm{mmoll}^{-1}\right)$ : $\mathrm{NaCl} 120, \mathrm{KCl} 5.4, \mathrm{CaCl}_{2}$ 2.2, $\mathrm{MgCl}_{2}$ 1.0, $\mathrm{NaHCO}_{3}$ 25.0, and dextrose 5.6. The bathing media were maintained at $37 \pm 0.3{ }^{\circ} \mathrm{C}$ and aerated with a mixture of $95 \% \mathrm{O}_{2}$ and $5 \% \mathrm{CO}_{2}$; the $\mathrm{pH}$ of the solution was in the range of 7.38-7.43. The hook fixing the upper end of the strips was connected to the lever of a force-displacement transducer, and the resting tension was adjusted to $0.25 \mathrm{~g}$, which is the optimal tension for inducing maximal contraction. ${ }^{14}$ Before the start of the experiments, the strips were allowed to equilibrate in the bathing media. During this time, the fluids were replaced three times with fresh media at approximately 10 -min intervals.

Isometric mechanical responses were displayed on a pen recorder. The contractile response to $30 \mathrm{mmoll}^{-1} \mathrm{~K}^{+}$was obtained first, and the strips were repeatedly washed with fresh media and equilibrated. The strips were placed between stimulating electrodes. Transmural electrical stimulation (TES) of $0.2 \mathrm{~ms}$ square-wave pulses at $0.2,0.5$ and $2 \mathrm{~Hz}$ for $40 \mathrm{~s}$ was applied to the strips. The strips were partially contracted with prostaglandin $F_{2 \alpha}$ to obtain a relaxation in response to TES. After the responses to TES were stabilized, test agents $\left(10^{-7} \mathrm{moll}^{-1}\right.$ atropine, $10^{-7} \mathrm{moll}^{-1}$ physostigmine and $10^{-4} \mathrm{moll}^{-1}$ L-NA) were added directly to the solution. Papaverine $\left(10^{-4} \mathrm{moll}^{-1}\right)$ was added at the end of the experiments to attain maximal relaxation. Results showed the TES-induced relaxations relative to those induced by papaverine.

\section{Statistics and drugs used}

Quantitative data are presented in the Results section for the in vivo study (four monkeys) and the in vitro study (six monkeys). The results are expressed as means \pm s.e. Statistical analyses were made with Student's paired $t$-test and Tukey's method after one-way analysis of variance. The drugs used were L-NA (Peptide Institute, Minoh, Japan), L-arginine (Kanto Chemical, Tokyo, Japan), hexamethonium bromide (Nacalai Tesque, Kyoto, Japan), physostigmine sulfate (Sigma, St Louis, MO, USA) and atropine sulfate (Tanabe, Osaka, Japan).

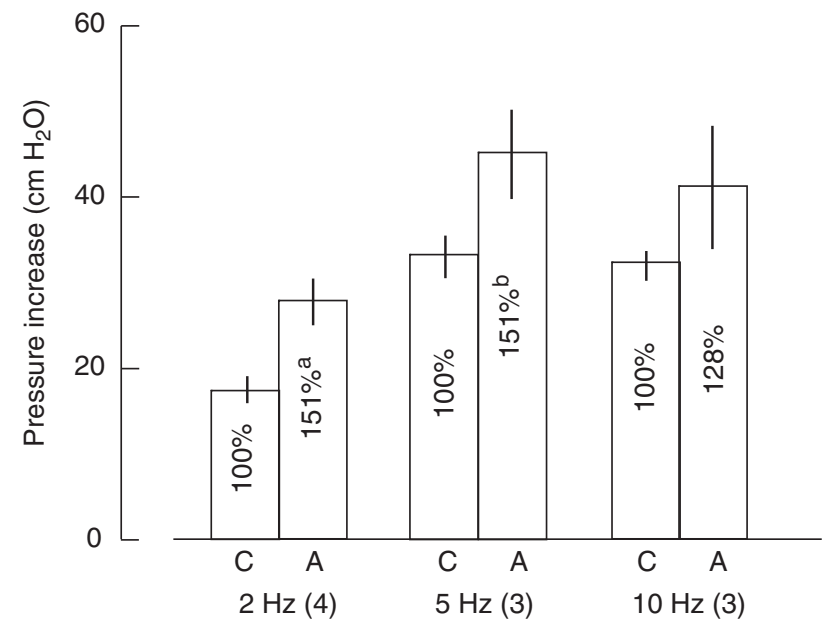

Figure 1 Effects of atropine ( $1 \mathrm{mg} \mathrm{kg}^{-1}$, i.v.) on the intracavernous pressure increase induced by electrical stimulation $(2,5$ and $10 \mathrm{~Hz})$ of the cavernous nerve in anesthetized monkeys. C, control; A, atropine. The ordinate denotes the pressure increase with respect to nerve stimulation. Numbers in parentheses indicate the number of monkeys used. Vertical bars represent s.e. of the means. Significantly different from control, ${ }^{a} P<0.001,{ }^{b} P<0.05$ (paired $t$-test).

\section{RESULTS}

\section{In vivo study}

Electrical stimulation $(2-10 \mathrm{~Hz}$ for $20 \mathrm{~s})$ of the cavernous nerve produced a frequency-dependent increase in the intracavernous pressure and penile erection in anesthetized monkeys. Treatment with atropine $\left(1 \mathrm{mg} \mathrm{kg}^{-1}\right.$, i.v.) enhanced, rather than reduced, the pressor response (Figure 1). The following study was carried out in monkeys treated with atropine.

Figure 2 summarizes the frequency $(1-10 \mathrm{~Hz})$-related increase in the intracavernous pressure induced by electrical nerve stimulation in four monkeys, in which reproducible responses were obtained. In two monkeys, the stimulation at $0.5 \mathrm{~Hz}$ elicited a slight but significant increase in pressure $\left(6\right.$ and $\left.8 \mathrm{~cm} \mathrm{H} \mathrm{H}_{2} \mathrm{O}\right)$. The maximal response was attained at 5 or $10 \mathrm{~Hz}$. Similar magnitudes of pressure increase occurred at $20 \mathrm{~Hz}(n=3)$. The stimulus frequency sufficient to induce a half-maximum response averaged $1.6 \mathrm{~Hz}$ and was obtained from the control curve shown in Figure 2. After electrical stimulation, the intracavernous pressure rose with a latency of 3-8 s, reached a plateau around $15 \mathrm{~s}$, and rapidly declined after termination of the stimulation. This transient pattern of responses was in contrast to those seen in anesthetized dogs, in which the pressure rise persisted for many minutes after nerve stimulation $(10$ or $20 \mathrm{~Hz})$ was terminated. ${ }^{15}$ In all the four monkeys tested, the pressure increase was transient at frequencies of $0.5-20 \mathrm{~Hz}$ irrespective of atropine treatment. The penis was visibly engorged and erect, in association with the increase in intracavernous pressure (Figure 3), and became detumescent when the pressure returned to the control level.

Intravenous administration of L-NA $\left(5 \mathrm{mg} \mathrm{kg}^{-1}\right)$ markedly inhibited the stimulation-induced increase in intracavernous pressure, and L-arginine ( $500 \mathrm{mg} \mathrm{kg}^{-1}$, i.v.) partially restored the response (Figure 2). Typical tracings of the pressure response as affected by L-NA and L-arginine are shown in Figure 4. The basal pressure was not affected by the administration of either L-NA or L-arginine. The erectile response was also depressed by L-NA. In one of four monkeys treated with L-NA, the pressure increase in response to electrical nerve stimulation was reversed to a decrease in the pressure, and L-arginine 


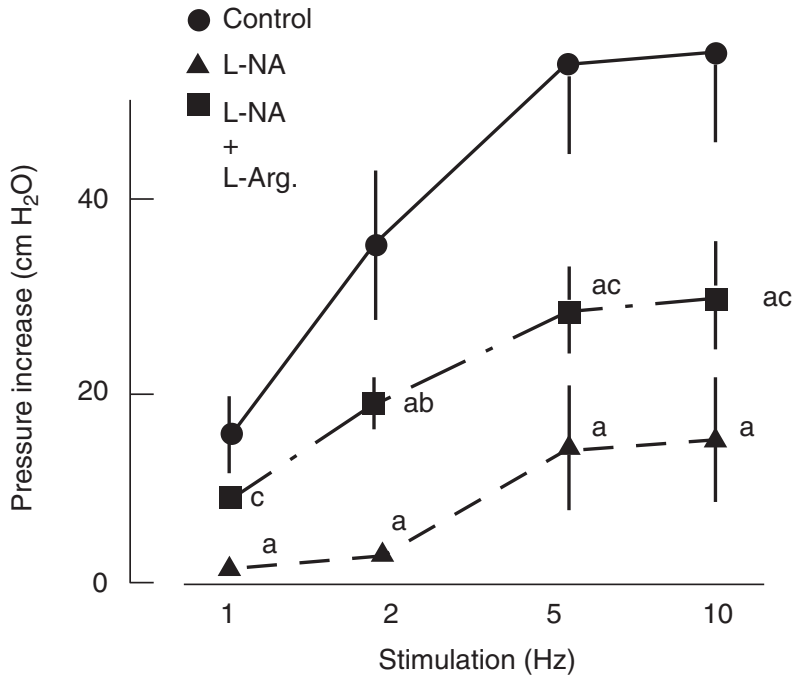

Figure 2 Modification by L-NA ( $5 \mathrm{mg} \mathrm{kg}^{-1}$, i.v.) and L-arginine (L-Arg., $500 \mathrm{mg} \mathrm{kg}^{-1}$, i.v.) of the intracavernous pressure increase induced by cavernous nerve stimulation $(1-10 \mathrm{~Hz})$ in anesthetized monkeys $(n=4)$. The ordinate denotes the pressure increase with respect to nerve stimulation. Vertical bars represent s.e. of the means. Significantly different from the value in control, ${ }^{a} P<0.01$; significantly different from the value with L-NA, ${ }^{\mathrm{b}} P<0.01,{ }^{\mathrm{c}} P<0.05$ (Tukey's method).
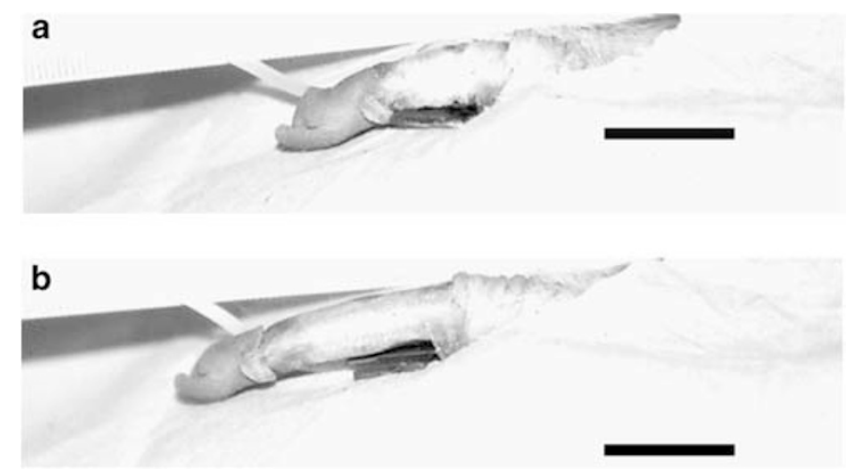

Figure 3 Engorgement of the penis in response to cavernous nerve stimulation in an anesthetized monkey: (a) before stimulation; (b) during stimulation $(10 \mathrm{~Hz})$, by which the maximal increase in intracavernous pressure was attained. The penis tumefied and erected, and then collapsed but remained tumescent. Bars $=20 \mathrm{~mm}$.

restored the pressor response (Figure 5). In two monkeys, hexamethonium $\left(4 \mathrm{mg} \mathrm{kg}^{-1}\right.$, i.v. $)$ suppressed the pressor response to nerve stimulation that had been restored by $\mathrm{L}$-arginine.

\section{In vitro study}

Transmural electrical stimulation produced a frequency-related relaxation at frequencies of $0.2,0.5$ and $2 \mathrm{~Hz}$ in the strips of the monkey corpus cavernosum partially contracted with prostaglandin $\mathrm{F}_{2 \alpha}$. Treatment with atropine at a concentration of $10^{-7} \mathrm{moll}^{-1}$ slightly but significantly potentiated relaxation at a frequency of $0.2 \mathrm{~Hz}$, whereas atropine did not affect relaxation at stimulation frequencies of 0.5 and $2 \mathrm{~Hz}$ (Figure 6, left). Treatment with $10^{-7} \mathrm{moll}^{-1}$ physostigmine significantly attenuated the stimulation-induced relaxation at frequencies of 0.5 and $2 \mathrm{~Hz}$ (Figure 6, middle). The stimulation-induced relaxation at $0.2,0.5$ and $2 \mathrm{~Hz}$ was markedly inhibited by treatment

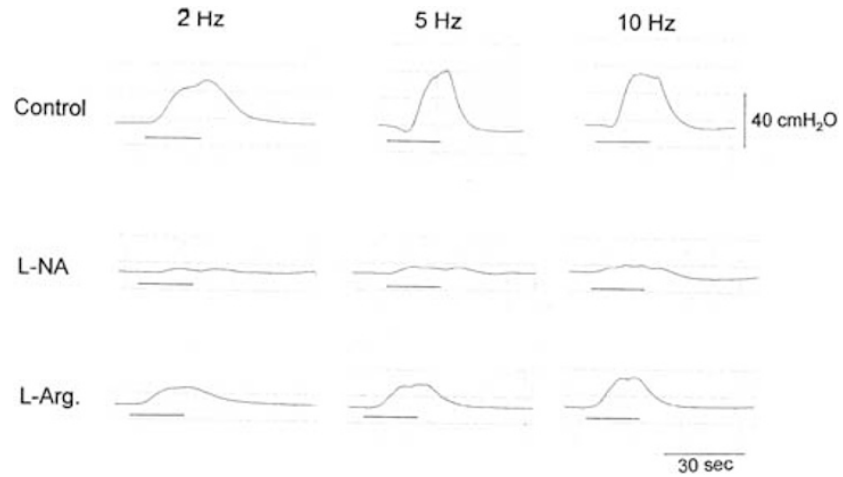

Figure 4 Typical tracings of the response of intracavernous pressure to electrical stimulation of the cavernous nerve $(2,5$ and $10 \mathrm{~Hz})$ before (control) and after L-NA ( $5 \mathrm{mg} \mathrm{kg}^{-1}$, i.v.) and L-NA plus L-arginine (L-Arg., $500 \mathrm{mg} \mathrm{kg}^{-1}$, i.v.) in an anesthetized monkey. Bars just under the tracings represent the application of nerve stimulation (20 s).

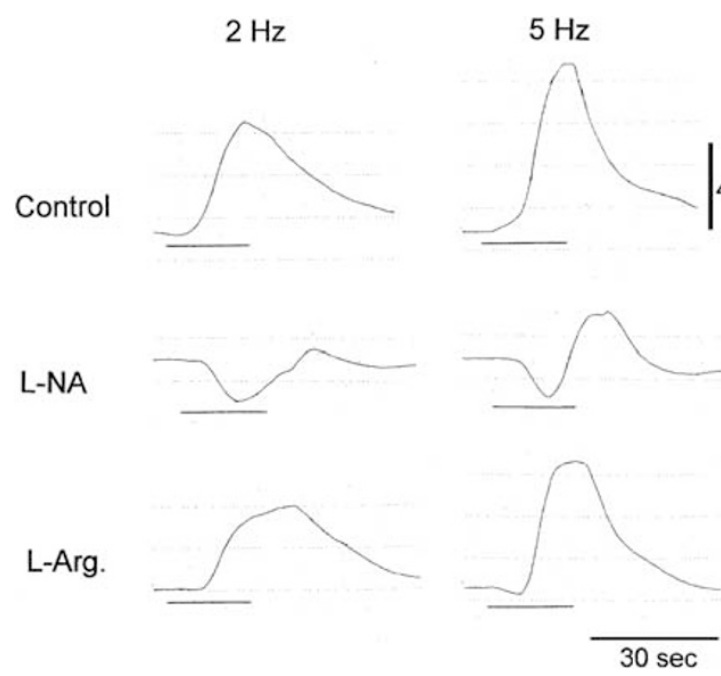

Figure 5 Responses of the intracavernous pressure to nerve stimulation at 2 and $5 \mathrm{~Hz}$ as affected by L-NA ( $5 \mathrm{mg} \mathrm{kg}^{-1}$, i.v.) and additional administration of L-arginine (L-Arg., $500 \mathrm{mg} \mathrm{kg}^{-1}$, i.v.) in an anesthetized monkey. L-NA reversed the pressor response to a depressor response, and the effect was antagonized by L-arginine. Bars just under the tracings represent the application of nerve stimulation (20s).

with the high concentration of L-NA $\left(10^{-4} \mathrm{moll}^{-1}\right.$, Figure 6 , right). Furthermore, the stimulation-induced relaxation was abolished by treatment with $3 \times 10^{-7} \mathrm{moll}^{-1}$ tetrodotoxin (Ayajiki et al., unpublished observation; $n=6$ ).

\section{DISCUSSION}

In anesthetized monkeys, the frequency-dependent increase in the intracavernous pressure by electrical stimulation of the cavernous nerve was depressed by L-NA and partially restored by L-arginine. The penile erection in association with the pressor response was also abolished by L-NA. In strips of the corpus cavernosum isolated from Japanese monkeys ${ }^{14}$ and humans, ${ }^{6,9,16}$ electrical field stimulation produced relaxation that was markedly inhibited by L-NA, but not D-NA, and L-arginine reversed the response. NADPH diaphorasepositive nerve fibers were also found in the monkey and human corpus cavernosum. ${ }^{14,17}$ Release of NO by electrical nerve stimulation 

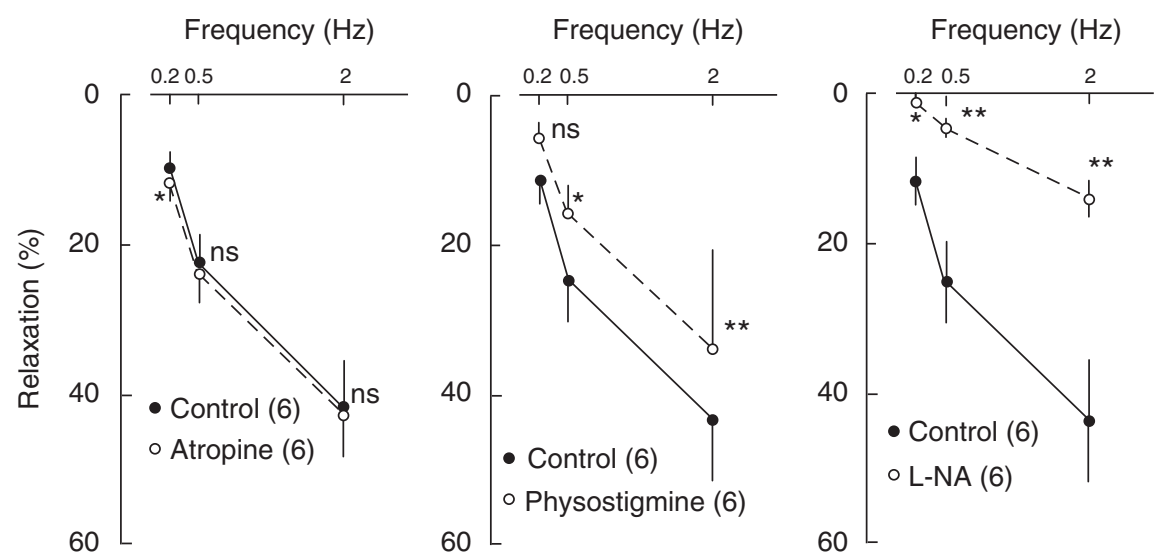

Figure 6 Modification by atropine $\left(10^{-7} \mathrm{~mol} \mathrm{I}^{-1}\right.$, left), physostigmine $\left(10^{-7} \mathrm{moll}^{-1}\right.$, middle) and $N^{G}$-nitro-L-arginine (L-NA, $10^{-4} \mathrm{moll}-1$, right) of the relaxation induced by transmural electrical stimulation $(0.2,0.5$ and $2 \mathrm{~Hz})$ in isolated monkey corpus cavernosum $(n=6)$. The ordinate denotes the relaxation with respect to transmural electrical stimulation. Vertical bars represent s.e. of the means. Significantly different from the value in control, ${ }^{*} P<0.05$, $* * P<0.01$ (paired $t$-test).

was shown in human corpora cavernosa. ${ }^{17}$ These findings support the hypothesis that NO derived from inhibitory nerves has a major role in inducing cavernous smooth muscle relaxation, intracavernous pressure increase and penile erection in primates. Intravenous L-NA and L-arginine did not appreciably change the basal pressure, suggesting that the quantity of NO tonically released from the nerve and the endothelium was insufficient, under current experimental conditions, to raise the intracavernous pressure.

In anesthetized dogs, electrical stimulation of the cavernous nerve has been shown to increase the intracavernous pressure in a frequency-related manner, and the pressure increase at high frequencies of 10 and $20 \mathrm{~Hz}$ can persist after cessation of nerve stimulation. ${ }^{15,18} \mathrm{By}$ contrast, the relaxant response to nitrergic nerve stimulation of isolated dog corpus cavernosum strips ceases rapidly after stimulation ends. ${ }^{19}$ We speculated that the differential pattern of the responses in vitro and in vivo could be explained by the NO released from the sinusoidal endothelium as a result of stretching, which is due to the intracavernous pressure increase induced by neurogenic NO. This sequence of events has been postulated by Hurt et al. ${ }^{11}$ However, this is not the case in monkeys, as both the intracavernous pressure response to nerve stimulation and the relaxant response of isolated cavernous strips to electrical field stimulation rapidly decayed after nerve stimulation was terminated. In monkey preparations in vitro and in vivo, the cavernous smooth muscle relaxation ${ }^{14}$ and intracavernous pressure increase (data not shown) persisted during nerve stimulation but faded after the stimulation was removed. These findings strongly suggest that nerve-derived NO primarily contributes to the initiation and maintenance of penile erection in monkeys. The possible involvement of neurogenic acetylcholine in releasing endothelial NO was excluded, as discussed below.

Intracavernous pressure in monkeys was increased by nerve stimulation at frequencies as low as $0.5 \mathrm{~Hz}$, and the stimulus frequency sufficient to induce half-maximal response was $1.6 \mathrm{~Hz}$. This was appreciably lower than the analogous frequency measured in dogs (about $7 \mathrm{~Hz}),{ }^{15}$ rabbits $(4-5 \mathrm{~Hz}),{ }^{1}$ rats (about $\left.2.5 \mathrm{~Hz}\right)^{20}$ and mice $\left(7.2 \mathrm{~Hz}\right.$ with stimulation intensity of 1.5 volts). ${ }^{21}$ The finding was confirmed in isolated monkey corpus cavernosum strips, in which electrical stimulation at $1 \mathrm{~Hz}$ induced marked relaxation at a magnitude close to the maximal level. ${ }^{14}$ Human cavernous strips also appear to be sensitive to neural stimulation (about $2 \mathrm{~Hz}$ ), ${ }^{9}$ although in vivo data have not been obtained. Penile erection in primates appears to be elicited by a physiological range of nitrergic nerve activation.

In some instances, treatment with L-NA reversed the intracavernous pressor response to nerve stimulation and converted it to a depressor response. L-arginine restored the pressor response. The observation of this result in a limited number of monkeys may reflect individual variation of antierectile innervation. The pelvic plexus contains not only parasympathetic but also sympathetic neurons. The pressor response may be induced by parasympathetic nitrergic nerve activation, whereas the depressor response may be derived from sympathetic nerve stimulation. In the isolated monkey corpus cavernosum, NO-mediated relaxation elicited by electrical nerve stimulation was potentiated by treatment with prazosin, ${ }^{14}$ suggesting that the activation of $\alpha_{1}$-adrenoceptors by neurogenic norepinephrine may counteract nitrergic relaxation. Cellek and Moncada ${ }^{22}$ hypothesized that adrenergic influences on the smooth muscle tone of human and rabbit corpora cavernosa are masked by powerful nitrergic innervation and are manifested only when NO production is impaired. This seems to be the case in monkey penile tissues in vivo, despite a lack of direct evidence in this study of the involvement of sympathetic innervation.

We have previously provided histochemical and physiological evidence in vivo, using a ganglionic blocking agent, that efferent nerves responsible for relaxation of the dog corpus cavernosum originate from ganglia proximal to the tissue but not directly from the pelvic plexus. ${ }^{23}$ The present finding that ganglionic blockade by hexamethonium depressed the NO-mediated intracavernous pressor response to electrical cavernous nerve stimulation may indicate that the monkey corpus cavernosum is also innervated by nitrergic nerves from the local ganglia, which receive neurons from the pelvic plexus.

It has been reported that acetylcholine produces relaxation of cavernous smooth muscle because of the release of NO from the sinusoidal endothelium in humans, ${ }^{13,24}$ dogs, ${ }^{25}$ rabbits $^{26}$ and rats. ${ }^{27}$ Evidence supporting the hypothesis that NO released by acetylcholine from cholinergic nerves participates in the relaxation of corpus cavernosum strips has not been found, ${ }^{25}$ whereas the intracavernous pressure response to nerve stimulation was reportedly endotheliumdependent and atropine-sensitive in anesthetized dogs. ${ }^{28}$ In this study, however, atropine did not reduce the intracavernous pressure increase induced by nerve stimulation in monkeys in vivo, suggesting that $\mathrm{NO}$ 
in an amount sufficient to increase the pressure is not liberated from the sinusoidal endothelium even if acetylcholine is released from cholinergic nerves. By contrast, atropine enhanced the stimulationinduced pressure increase. Prejunctional muscarinic receptors located in nitrergic nerves are believed to inhibit the release of neurogenic NO in monkey and porcine cerebral arteries in vitro ${ }^{29,30}$ and in monkey ophthalmic arteries in vivo. ${ }^{31}$ The present and previous studies ${ }^{14}$ that used isolated monkey corpus cavernosum have shown that TESinduced tetorodotoxin-sensitive relaxation was markedly attenuated by treatment with L-NA. These findings suggest that the relaxation in monkey corpus cavernosum caused by electrical stimulation is neurogenic and that the relaxing factors released from nerve terminals consist primarily of NO. The present in vitro study using isolated corpus cavernosum also showed that atropine treatment added to TES at a frequency of only $0.2 \mathrm{~Hz}$ potentiated relaxation. Furthermore, relaxation was attenuated by treatment with physostigmine, a cholinesterase inhibitor. Therefore, atropine enhancement of the neurogenic response in the monkey penis is thought to result from the elimination of inhibitory action of endogenous acetylcholine on prejunctional muscarinic receptors. The weaker enhancing effect of atropine on the stimulation-induced relaxation in corpus cavernosum in vitro, compared with that on the stimulation-induced increase in the pressure of corpus cavernosum in vivo, led us to speculate that the amount of endogenous acetylcholine in the cavernous tissue may be decreased by degradation after isolation.

In summary, in anesthetized monkeys, electrical stimulation of the cavernous nerve at low frequencies $(0.5-2 \mathrm{~Hz})$ elicited penile engorgement and a NO-mediated increase in the intracavernous pressure. The initiation and maintenance of increased intracavernous pressure and penile erection could be caused, as in other animals, by NO released from inhibitory nerves. By contrast, this study is the first to show that prejunctional muscarinic receptor stimulation by endogenous acetylcholine from cholinergic nerves may inhibit the nitrergic function responsible for penile erection in primates. A detailed analysis of muscarinic receptor subtypes remains to be performed. Nitrergic nerves from ganglia close to the corpus cavernosum, but not directly from the pelvic plexus, appear to control penile function. The intracavernous pressure decrease resulting from cavernous nerve stimulation may be mediated by norepinephrine from adrenergic nerves.

\section{CONFLICT OF INTEREST}

The authors declare no conflict of interest.

\section{ACKNOWLEDGEMENTS}

This study was supported by Grants in part by the Hoh-an Sha Foundation and by the Smoking Foundation.

1 Ignarro LJ, Bush PA, Buga GM, Wood KS, Fukuto JM, Rajfer J. Nitric oxide and cyclic GMP formation upon electrical field stimulation cause relaxation of corpus cavernosum smooth muscle. Biochem Biophys Res Commun 1990; 170: 843-850.

2 Burnett AL, Lowenstein CJ, Bredt DS, Chang TSK, Snyder SH. Nitric oxide: a physiologic mediator of penile erection. Science 1992; 257: 401-403.

3 Andersson KE, Wagner G. Physiology of penile erection. Physiol Rev 1995; 75 : 191-236.

4 Burnett AL. Nitric oxide in the penis: physiology and pathology. J Urol 1997; 157: 320-324
5 Toda N, Okamura T. The pharmacology of nitric oxide in the peripheral nervous system of blood vessels. Pharmacol Rev 2003; 55: 271-324.

6 Holmquist $\mathrm{F}$, Hedlund $\mathrm{H}$, Andersson KE. Characterization of inhibitory neurotransmission in the isolated corpus cavernosum from rabbit and man. J Physiol 1992; 449: 295-311.

7 Kim N, Azadzoi KM, Goldstein I, Saenz de Tejada I. A nitric oxide-like factor mediates nonadrenergic-noncholinergic neurogenic relaxation of penile corpus cavernosum smooth muscle. J Clin Invest 1991; 88: 112-118.

8 Pickard RS, Powell PH, Zar MA. The effect of inhibitors of nitric oxide biosynthesis and cyclic GMP formation on nerve-evoked relaxation of human carvernosal smooth muscle. Br J Pharmacol 1991; 104: 755-759.

9 Rajfer J, Aronson WJ, Bush PA, Dorey FJ, Ignarro LJ. Nitric oxide as a mediator of relaxation of the corpus cavernosum in response to nonadrenergic, noncholinergic neurotransmission. N Engl J Med 1992; 326: 90-94.

10 Boolell M, Allen MJ, Ballard SA, Gepi-Attee S, Muirhead GJ, Naylor AM, Osterloh IH, Gingell C. Sildenafil: an orally active type 5 cyclic GMP-specific phosphodiesterase inhibitor for the treatment of penile erectile dysfunction. Int J Impot Res 1996; 8: 47-52.

11 Hurt KJ, Musicki B, Palese MA, Crone JK, Becker RE, Moriarity JL, Snyder SH, Burnett AL. Akt-dependent phosphorylation of endothelial nitric-oxide synthase mediates penile erection. Proc Natl Acad Sci USA 2002; 99: 4061-4066.

12 Hedlund $\mathrm{P}$, Ny L, Alm $\mathrm{P}$, Andersson KE. Cholinergic nerves in human corpus cavernosum and spongiosum contain nitric oxide synthase and heme oxygenase. J Urol 2000; 164: 868-875.

13 Saenz de Tejada I, Blanco R, Goldstein I, Azadzoi K, de las Morenas A, Krane RJ, Cohen RA. Cholinergic neurotransmission in human corpus cavernosum. I. Responses of isolated tissue. Am J Physiol 1988; 254: H459-H467.

14 Okamura T, Ayajiki K, Toda N. Monkey corpus cavernosum relaxation mediated by NO and other relaxing factor derived from nerves. Am J Physiol Heart Circ Physiol 1998; 274: H1075-H1081.

15 Ayajiki K, Hayashida H, Okamura T, Toda N. Pelvic nerve stimulation-induced pressor responses in corpus cavernosum of anesthetized dogs. Am J Physiol Heart Circ Physiol 1997; 273: H2141-H2145.

$16 \mathrm{Knispel} \mathrm{HH}$, Goessl C, Beckmann R. Nitric oxide mediates relaxation in rabbit and human corpus cavernosum smooth muscle. Urol Res 1992; 20: 253-257.

17 Leone AM, Wiklund NP, Hokfelt T, Brundin L, Moncada S. Release of nitric oxide by nerve stimulation in the human urogenital tract. Neuroreport 1994; 5: 733-736.

18 Trigo-Rocha F, Aronson WJ, Hohenfellner M, Ignarro LJ, Rajfer J, Lue TF. Nitric oxide and CGMP: mediators of pelvic nerve-stimulated erection in dogs. Am J Physiol Heart Circ Physiol 1993; 264: H419-H422.

19 Hayashida H, Okamura T, Tomoyoshi T, Toda N. Neurogenic nitric oxide mediates relaxation of canine corpus cavernosum. J Urol 1996; 155: 1122-1127.

20 Cellek S, Rodrigo J, Lobos E, Fernandez P, Serrano J, Moncada S. Selective nitrergic neurodegeneration in diabetes mellitus-a nitric oxide-dependent phenomenon. Br J Pharmacol 1999; 128: 1804-1812.

21 Mizusawa $\mathrm{H}$, Hedlund $\mathrm{P}$, Hakansson A, Alm P, Andersson KE. Morphological and functional in vitro and in vivo characterization of the mouse corpus cavernosum. Br J Pharmacol 2001; 132: 1333-1341.

22 Cellek S, Moncada S. Nitrergic control of peripheral sympathetic responses in the human corpus cavernosum: a comparison with other species. Proc Natl Acad Sci USA 1997; 94: 8226-8231.

23 Ayajiki K, Hayashida H, Okamura T, Toda N. Influence of denervation on neurogenic inhibitory response of corpus cavernosum and nitric oxide synthase histochemistry. Brain Res 1999; 825: 14-21.

24 Azadzoi KM, Kim N, Brown ML, Goldstein I, Cohen RA, Saenz de Tejada I. Endothelium-derived nitric oxide and cyclooxygenase products modulate corpus cavernosum smooth muscle tone. J Urol 1992; 147: 220-225.

25 Okamura T, Ayajiki K, Fujioka H, Toda M, Fujimiya M, Toda N. Effects of endothelial impairment by saponin on the responses to vasodilators and nitrergic nerve stimulation in isolated canine corpus cavernosum. Br J Pharmacol 1999; 127: 802-808.

26 Knispel HH, Goessl C, Beckmann R. Basal and acetylcholine-stimulated nitric oxide formation mediates relaxation of rabbit cavernous smooth muscle. J Urol 1991; 146: 1429-1433.

27 Champion HC, Bivalacqua TJ, Hyman AL, Ignarro LJ, Hellstrom WJ, Kadowitz PJ. Gene transfer of endothelial nitric oxide synthase to the penis augments erectile responses in the aged rat. Proc Natl Acad Sci USA 1999; 96: 11648-11652.

28 Trigo-Rocha F, Hsu GL, Donatucci CF, Lue TF. The role of cyclic adenosine monophosphate, cyclic guanosine monophosphate, endothelium and nonadrenergic, noncholinergic neurotransmission in canine penile erection. J Urol 1993; 149: 872-877.

29 Toda N, Ayajiki K, Okamura T. Inhibition of nitroxidergic nerve function by neurogenic acetylcholine in monkey cerebral arteries. J Physiol 1997; 498: 453-461.

30 Tanaka T, Okamura T, Handa J, Toda N. Neurogenic vasodilation mediated by nitric oxide in porcine cerebral arteries. J Cardiovasc Pharmacol 1999; 33: 56-64.

31 Ayajiki K, Tanaka T, Okamura T, Toda N. Evidence for nitroxidergic innervation in monkey ophthalmic arteries in vivo and in vitro. Am J Physiol Heart Circ Physiol 2000; 279: 2006-2012. 